\title{
Filosofia do design instrucional: uma análise meta-teórica sobre método de comparação entre modalidade de mídias ${ }^{1}$
}

\section{Philosophy of instructional design: a meta-theoretical analysis on media modality comparing method}

\author{
Antônio M. Fontoura, Marcos N. Beccari, Tiago de L. Oliveira
}

\begin{abstract}
Metodologia de Design Instrucional, Filosofia do Design, Pós-Positivismo, método de comparação entre modalidade de mídias

O propósito deste artigo é discutir um dos métodos comparativos mais utilizados em pesquisa de Design Instrucional (Mayer, 2005) sob os pressupostos da intitulada Filosofia do Design (Love, 2000). Iniciando com um breve panorama histórico da pesquisa em design, realizamos uma revisão bibliográfica básica acerca da Filosofia do Design e do Design Instrucional e, por fim, levantamos alguns questionamentos pontuais sobre o método vigente. Partimos da hipótese de que os testes de comparação entre modalidades de mídias (estática e dinâmica) no Design Instrucional podem se tornar meros instrumentos de comprovação inferencial, sendo frequentemente replicados em pesquisas diversas. Este trabalho, contudo, não apresenta uma conclusão definitiva, mas apenas procura sinalizar algumas lacunas e possíveis desdobramentos do método em questão.
\end{abstract}

Instructional Design Method, Philosophy of Design, Post-Positivism, media modality comparing method

The purpose of this article is to discuss one of the most used comparative methods in research in the Instructional Design field (Mayer, 1998) under the assumptions of the entitled Philosophy of Design (Love, 2000). Starting with a brief historical overview of Design Research, we conducted a basic literature review on Philosophy of Design and Instructional Design and, finally, we raise some specific questions about the mentioned method. Our hypothesis is that the comparison tests between the types of media (static and dynamic) in Instructional Design can become mere tools of inferential confirmation, often replicated in several studies. This work, however, does not present a definitive conclusion, but only seeks to identify some gaps and possible developments of the method in question.

\section{Introdução}

Filosofia do Design é uma disciplina que se propõe a investigar as teorias de Design de maneira meta-teórica em relação a tal objeto de estudo (Love, 2000). Difere-se assim da Teoria do Design em si, que é uma disciplina preocupada com Metodologia de Design, Métodos de Design, História do Design e outras subdisciplinas que atribuem um papel, uma coerência e uma validade ao design enquanto área de pesquisa (idem).

Inseridos no contexto de Mestrado (PPG-Design UFPR), notamos que alguns métodos existentes no denominado 'Design Instrucional' são repetidamente aplicados em pesquisas diversas. Dentre os métodos mais recorrentes, selecionamos os testes para avaliar a eficácia de mídias dinâmicas (i.e. animações) em comparação com mídias estáticas (majoritariamente imagens impressas), sendo especialmente a proposta de Mayer (2005) aquela a ser discutida, sob o viés da Filosofia do Design, neste trabalho.

Partindo da hipótese de que mídias dinâmicas são mais eficazes ao ensino de conteúdos dinâmicos, a abordagem de Mayer consiste em separar determinada amostragem em dois grupos, um de controle e outro de teste, cada qual dispondo de uma mídia diferente voltada ao

\footnotetext{
${ }^{1}$ Esse artigo é uma versão revista, ampliada e atualizado do trabalho Uma abordagem filosófica acerca do método de comparação entre modalidade de mídias no design instrucional, apresentado no $5^{\circ}$ Congresso Internacional de Design da Informação (Florianópolis, 2011).
} 
aprendizado de um mesmo conteúdo. Embora tal abordagem metodológica também seja recorrente em outras vertentes além do Design Instrucional, pouco se discute a respeito de suas bases epistemológicas e cada vez mais se reaplica o mesmo método como sendo um caminho seguro e confiável.

Frente a isso, o propósito deste artigo é analisar, no que concerne o Design Instrucional, o método de comparação entre mídias estáticas e dinâmicas sob a ótica da Filosofia do Design. Partimos da hipótese de que o método em questão tornou-se um instrumento de comprovação inferencial, sem haver reflexão de seus precedentes teórico-metodológicos. Por meio de uma revisão bibliográfica básica (alicerçada à Filosofia do Design e ao Design Instrucional), pretendemos levantar alguns questionamentos pontuais sobre o método vigente.

Em um primeiro momento, apresentamos um breve panorama histórico da pesquisa em Design no intuito de contextualizar e explicar o recente campo da Filosofia do Design, focando-nos desde o início nas possíveis contribuições filosóficas aos processos envolvidos nos métodos de Design Instrucional. Em seguida, elegemos e descrevemos o método comparativo de Mayer como sendo o nosso objeto de estudo. Por fim, com base em ambas as revisões bibliográficas, retomaremos nosso pressuposto inicial ao levantarmos algumas questões a serem respondidas e desdobradas futuramente.

\section{Um breve panorama histórico sobre a pesquisa em Design}

Antes de apresentarmos os possíveis paradigmas do Design Instrucional, julgamos oportuno traçar brevemente algumas das premissas históricas da Pesquisa em Design que são necessárias para o entendimento daqueles pretendidos paradigmas.

Em um contexto onde o discurso moderno imperava na Europa, a form follows function ou funcionalismo foi a doutrina predominante por várias décadas na arquitetura e no design (Fontoura, 1997). Segundo Cross (2007), a pesquisa em Design foi inaugurada somente com a primeira Conference on Design Methods, realizada em Londres em 1962. Na tentativa de consolidar a metodologia de Design como disciplina científica, o movimento Design Methods procurava substituir o processo artístico-intuitivo, ainda recorrente, pela aplicação de procedimentos puramente científicos e racionais: métodos de pesquisa operacional, técnicas de gestão de tomada de decisão, técnicas de criatividade, etc.

Se na década de 1960 o lema era estandardização e racionalização, a década de 1970 foi marcada pela rejeição dos métodos científicos de Design (idem). Mas esta segunda geração de pesquisadores, recorrendo à ética pragmatista da razoabilidade, somente facilitou as pesquisas aplicadas e manteve o status científico do Design com o denominado Engineering Design. Isso possibilitou, na década de 1980, um período de sólida concretização da Pesquisa em Design com o surgimento dos primeiros periódicos científicos de Pesquisa em Design². Por outro lado, contra o pragmatismo do movimento Engineering Design, os italianos do II Nuovo Design ${ }^{3}$ pregavam o retorno ao método indutivo através de um processo de mudança paradigmática na metodologia do projeto. Tratava-se de um posicionamento crítico e reformista que seguia um caminho distinto do emergente Design Thinking, uma terceira vertente da década de 1980 que buscava estudar o Design por conta própria, isto é, com base na visão de que o Design tem seus próprios objetos de estudo e suas próprias maneiras para conhecê-los.

É apenas na década de 1990 que, consoante Cross (2007), o Design atingiria a maioridade com sua significativa expansão de congressos e periódicos científicos. Por outro lado, é neste mesmo contexto que surge a autointitulada Philosophy of Design, um movimento que acusa uma tendência fragmentada de confusão, fusão e multiplicidade nas teorias de Design.

\footnotetext{
${ }^{2}$ Design Studies (1979), Design Issues (1984) e Research in Engineering Design (1989).

${ }^{3}$ Movimento contemporâneo no campo do design que se propunha a questionar os métodos tradicionais de concepção de objetos e seus resultados (Fontoura, 1997). Entre os grupos que iniciaram tais manifestações e que são genericamente categorizados como pós-modernos estão: o grupo Archizoom (1966-1974), o grupo Studio Alchimia (1979) e o grupo Memphis (1981).
} 


\section{Filosofia do Design}

...existe uma quantia considerável de confusão com relação à base fundamentadora de diversas teorias, conceitos e métodos. (...) vários autores estão injustificadamente fundindo conceitos elaborados a partir de uma diversidade de fontes (...) [gerando] uma multiplicidade desnecessária de teorias e conceitos de design. (...) Com isso, as terminologias de pesquisas de design tornaram-se desnecessárias e inutilmente confusas e imprecisas. (Love, 2000: 295) .

Antes de investigar de que forma os pesquisadores em Design estão fundindo muitos conceitos inapropriadamente, Love (2000) procura identificar como é que essas fusões podem acontecer e como elas podem levar ao desenvolvimento incorreto de teorias em Design: se $A$ é relacionado com $B$ e $B$ é relacionado $\operatorname{com} C$, então $A$ é relacionado com $C$. Trata-se inicialmente de um equívoco inferencial no relacionamento entre as entidades abstratas - 'Um gato tem quatro patas e um cachorro tem quatro patas, logo um gato é um cachorro' (Love, 2000: 297).

Embora se recorra à retórica socrática primária ${ }^{5}$, a intenção do autor é mostrar que o raciocínio lógico pode nos levar a associações inferenciais que, uma vez tomadas como fundamentos teóricos, podem gerar conclusões equivocadas. Por exemplo: 'Designers pensam e psicólogos cognitivos estudam o pensamento, logo pesquisas em Design encontram-se dentro da área de Psicologia Cognitiva' (idem). Por mais que esse tipo de dedução não ocorra de maneira tão ingênua no Design, a desconfiança de Love aponta para a produção descontrolada de literatura relacionada às pesquisas de Design desde a década de 1950. Mesmo com centenas de livros e artigos publicados a cada ano, as teorias estariam sendo propostas especulativamente a partir de uma ampla variedade de perspectivas teóricas que, no entanto, não seriam suficientes para uma análise epistemológica e ontológica (Love, 2000: 298). Isso porque haveria pouca concordância em aspectos fundamentais (como na definição da palavra design, por exemplo), o que não impediria, porém, que as pesquisas continuassem sendo desenvolvidas de maneira fragmentada em diversas províncias teóricas (idem).

Seguindo esse raciocínio, as associações equivocadas e inferenciais se tornariam inevitáveis em um desenvolvimento teórico com base temporal, isto é, na medida em que se tenta descrever padrões em teorias feitas por gerações anteriores (idem). Na tentativa de mapear alguns temas que eram desenvolvidos de modo sequencial, cada qual encarregado de concertar a falha de seu antecessor, Cross (1984) foi um dos primeiros autores a propor uma 'simplificação no paradigma da pesquisa em Design'. Assim, o autor identificou alguns paradigmas cronológicos que se utilizam dos mesmos termos e conceitos para se referirem a significados diferentes (de acordo com cada contexto histórico). A linha temática desses paradigmas percorreria a seguinte direção: gestão no processo de Design; estrutura dos problemas de Design; natureza das atividades de Design; reflexões sobre os conceitos fundamentais de Design (idem). Love (2000) sugeriu a adição de outros dois temas ao final dessa evolução paradigmática: conhecimento sobre o ambiente em que o Design ocorre; conhecimento necessário para a concepção do Design (i. e. sobre objetos e processos de Design ${ }^{6}$ ). Dez anos após sua análise paradigmática, Cross (1993) abandonou sua abordagem kuhniana (i. e. referente aos paradigmas históricos de Thomas Kuhn) ao reconhecer aquelas fusões terminológicas descritas por Love no desenvolvimento 'conflacionário' de teorias que atravessam simultaneamente todos os paradigmas, o que geraria uma confusão paradigmática. Dixon (1988), por outro lado, confrontou essa confusão terminológica argumentando que as pesquisas em Design situar-se-iam num estágio pré-teórico, isto é, com o propósito de apenas estabelecer teorias cientificamente 'testáveis' que, no entanto, ainda se encontrariam impossíveis de serem validadas e aplicadas na prática (idem).

De todo modo, não é difícil notar uma tendência pós-positivista em grande parte dos pesquisadores - incluindo Love - proponentes de uma abordagem filosófica sobre as teorias de Design. Representado principalmente por Karl Popper e Thomas Kuhn, o pós-positivismo (também denominado pós-empirismo) é uma corrente filosófica que procura criticar e aperfeiçoar a lógica positivista-empirista de maneira meta-teórica (Zammito, 2004). Seguindo o princípio da refutabilidade de Popper, os filósofos do design declaram que é impossível verificar se uma teoria é verdadeira, embora seja possível identificar falsas teorias quando dispostas de um modo favorável à refutação. A perspectiva de Kuhn, por sua vez, é adotada com a concepção de que não apenas as teorias individuais, mas também todas as visões de mundo devem mudar em

\footnotetext{
${ }^{4}$ Esta e as demais citações de Love foram traduzidas livremente pelos autores deste trabalho.

${ }^{5}$ Quando Sócrates pediu uma definição de 'homem' para seus alunos, Platão disse que o homem é um animal bípede e

sem penas. Então Sócrates pegou uma galinha, arrancou suas penas e disse 'eis o homem de Platão'. Cf. Platão, 2001.

${ }^{6}$ Cf. HUBKA; EDER, 1990.
} 
relação às evidências apresentadas em cada paradigma histórico-cultural. Esse argumento é defendido, por exemplo, na investigação de Margolin (1992) sobre as fundamentações de base cultural que estão por trás da História do Design.

Recorrente nas ciências sociais por razões práticas e conceituais, o pós-positivismo não deve ser entendido como uma forma de relativismo puro, pois ainda preserva muitos fundamentos do positivismo: o realismo ontológico, o desejo pela verdade objetiva e o uso da metodologia experimental (Philips; Burbules, 2000). Ainda assim, a singularidade pós-positivista dos filósofos do design reside na crença de que, de modo geral, o conhecimento humano não é baseado em verdades incontestáveis, mas somente em hipóteses e processos heurísticos (Love, 1998).

Se construirmos brevemente uma linha cronológica sobre a influência pós-positivista na Filosofia do Design, podemos começar com a pesquisa de Thomas e Carroll (1979), que partia da hipótese de que o Design é mais bem concebido por teorias que valorizam uma dimensão psicológica e individual. Como desdobramento disso, Daley (1982) passou a analisar o papel dos objetos nessa dimensão psicológica, enquanto Dilnot (1982) constatava que as limitações das definições de design geralmente excluem o contexto social nos quais estão inseridas. Isso motivou Broadbent (1984) a discutir criticamente as teorias construídas em Design, influenciando diretamente as investigações de Coyne (1990) que assumiam cada vez mais um caráter póspositivista. Pouco tempo depois, Sargent (1994) propôs pela primeira vez uma discussão metateórica para argumentar sobre a impossibilidade de unificação entre ciência e Design, alegando a existência de uma incomensurabilidade de pontos de vista na pesquisa em Design. Na mesma direção, Liddament (1999) se preocupava com a natureza "codificada" e "computacional" das pesquisas em Design como uma limitação ao desenvolvimento da ontologia, epistemologia e metodologia de Design. Simultaneamente, Galle (1999) explorou o modo pelo qual a definição de Design tornou-se dependente da explicação de agentes humanos em diferentes situações de interação. Por fim, é igualmente válido mencionarmos a nova perspectiva proposta por Oxman (1999) para uma educação em Design focada na natureza dialética da palavra design, associando teorias cognitivas com a epistemologia pós-positivista.

\section{Método de comparação entre modalidade de mídias}

Um dos possíveis conceitos para Design Instrucional, segundo Smith e Ragan (1995), é o de processo sistemático e reflexivo de tradução (grifo nosso) de princípios de aprendizado em planos para materiais e atividades instrucionais. Sendo assim, também é possível considerar o Design Instrucional como sendo uma subárea do Design da Informação, estando ambos inseridos em um grande campo de tradução visual denominado 'Design Gráfico'. Contudo, convém pontuarmos que, assim como na pesquisa em Design como um todo, há uma série de divergências sobre a definição dos referidos termos, conforme Love (2000) já havia previsto. Adotando como base, em todo caso, o conceito de Smith et. al., o design instrucional se baseia em teorias do aprendizado. É por isso que, de acordo com Ertmer et. al. (1993), os principais fundamentos que servem de base para 0 design instrucional provêm de teorias de aprendizagem: a comportamental (Behaviorismo), a cognitiva (Cognitivismo) e a construtivista (Construtivismo).

Se esboçarmos uma rápida revisão histórica, apoiando-nos em Burton et. al. (1996), veremos que o Behaviorismo teve seu início em meados dos anos $20 \mathrm{com}$ os trabalhos de Mateer (1918), Watson e Rayner (1920) e Cason (1922), culminando nas reconhecidas pesquisas do psicólogo Skinner (1938). Embora o design instrucional tenha nascido dentro dessa conjuntura behaviorista, foi somente em meados dos anos 50 que se iniciou uma mudança de paradigma do Behaviorismo para o Cognitivismo (Burton et. al., 1996). O principal motivo para tal mudança foi o fato do primeiro não conseguir responder de maneira eficaz como se dá o processo de aprendizado a nível cognitivo, haja vista que, para o behaviorismo, o aprendizado ocorre através da mudança de comportamento visível (Jonassen, 1991). O cognitivismo, por sua vez, não encara o comportamento como uma caixa preta - ponto de vista este que levou tanto psicólogos quanto educadores a adotarem essa nova teoria do aprendizado, atribuindo maior ênfase aos processos cognitivos do aprendiz e não tanto em seu comportamento em si.

Em se tratando das pesquisas realizadas neste cenário, o modelo comportamental permitia, de maneira relativamente simples, garantir a sua própria eficácia - era fácil verificar se houve aquisição de conhecimento e se o aprendiz manifestava este ou aquele comportamento. A psicologia cognitiva, por outro lado, passou a buscar respostas a eventos que não são sempre 'visíveis a olho nu'. Deste modo, seguindo o modelo cientificista e pós-positivista, há na última 
abordagem a necessidade de uma coleta de evidências empíricas que comprovem uma conjectura ou um pressuposto teórico.

Dentre as teorias geradas no campo da psicologia cognitiva, existem algumas que influenciaram diretamente os designers instrucionais. Uma delas é a teoria da 'capacidade limitada', segundo a qual o ser humano só é capaz de processar uma quantidade limitada de informação por vez - caso contrário, ele ficaria 'sobrecarregado cognitivamente', acarretando falhas no aprendizado (Baddeley, 1998; Sweller, 1999). Partindo deste pressuposto, Paivio (1986) propôs o denominado 'princípio dual' (dual-coding) ao afirmar que cada canal de processamento de informação humano (basicamente o 'visual' e o 'auditivo') possui uma capacidade limitada de informação a ser processada. Finalmente, um desdobramento recente desta abordagem teórica é o intitulado 'princípio Multimídia de Mayer'. Em linhas gerais, parte-se da premissa de que as pessoas aprendem de maneira mais profunda (eficaz e eficiente) quando o material instrucional possui imagens e textos ao invés de apenas um deles isoladamente (Mayer, 2005). O sentido do termo Multimídia, pois, se refere à coexistência de duas mídias, a visual e a textual, sendo que a visual pode ser tanto estática (no caso de imagens em livros, por exemplo) quando dinâmicas (no caso de animações, vídeos, etc.), além de outras possíveis intersecções multimídias - por exemplo, o texto pode ser apresentado de maneira fonológica, fornecendo um conteúdo a ser captado por nosso aparelho auditivo.

O fato é que uma das atuais preocupações no design instrucional não se refere tanto à veracidade do princípio multimídia, mas sim na distinção de qual combinação de mídias pode mais adequada em uma situação específica - animação aliada a textos explicativos (podendo aqui ser apresentado de maneira escrita ou em forma de locução) ou imagens estáticas. Logo, o princípio multimídia raramente é questionado e o método de comparação de mídias se torna cada vez mais recorrente na literatura, em quase todos os casos seguindo o padrão adotado por Mayer e seus sucessores.

Sublinhamos o conteúdo dos testes mais conhecidos do autor: o sistema de freio de um carro, a formação de um relâmpago, uma bomba de ar e o pulmão humano (Mayer; Moreno, 2002). Em todos os casos, o método de comparação da modalidade de mídias é repetido da seguinte forma: inicialmente, separa-se a amostra em dois grupos, um de controle e um experimental, variando em alguns casos dependendo de quantas variáveis estão sendo consideradas. Cada grupo é exposto a uma instrução diferente e, em seguida, os aprendizes são requisitados a resolverem um exercício baseado na instrução recém-apresentada. As instruções podem variar de acordo com a modalidade ou com as variáveis envolvidas - por exemplo, na comparação entre uma animação com texto em forma de legenda e outra animação com texto em forma de locução, a modalidade é a mesma, mas há a inserção de uma nova variável cujos efeitos alteram o aprendizado. Por fim, apoiando-se a partir de então às premissas teóricas da psicologia cognitiva, os resultados obtidos fundamentam conclusões a respeito dos possíveis processos cognitivos que ocorreram durante a resolução dos problemas seguindo determinada instrução.

\section{Questionamentos filosóficos}

Love (2000) nos mostra que, ao ignorarmos as dimensões epistemológicas de métodos preestabelecidos, o raciocínio associativo pode nos levar a deduções impróprias que, uma vez tomadas como fundamentos teóricos, acabam reforçando uma simples inferência. Especificamente no Design Instrucional, as inferências podem ser tão recorrentes quanto às incoerências apontadas por Love em relação às teorias de Design. Através de avaliações cognitivas de comportamento, uma série de conjecturas indiretas (não reveladas diretamente nos testes) é postulada para explicar os motivos que levaram a determinado resultado. Não é difícil encontrar casos, por exemplo, onde um grupo de pessoas possui mais repertório ou cultura visual do que o grupo correspondente, tornando assim o teste previamente inválido em relação a seus objetivos. No âmbito da pedagogia da informática, conforme descreve Dallacosta (1998), a habilidade em informática é determinante no aproveitamento do usuário com relação à mídia dinâmica. Logo, o público-alvo escolhido para realizar as tarefas é também uma questão determinante: muitas vezes a escolha do público é aleatória e sem precedentes. Evidentemente, isso se torna decisivo nos resultados e conclusões geradas pelos testes.

Tversky et. al. (2002) afirma que muitas das pesquisas feitas no campo do design instrucional e psicologia cognitiva não são confiáveis. Uma das principais críticas feitas pelo autor a tais experimentos está relacionada à quantidade de informação apresentada pela mídia estática em 
relação à mídia dinâmica. Em muitos casos as animações apresentam mais informações do que seu equivalente estático, tornando o teste questionável na medida em que as mídias não são compatíveis (idem). Corroborando com o último raciocínio, Hegarty (2004) compara, por revisão bibliográfica, vinte experimentos que se propõem a mensurar a eficácia de animações em relação a imagens estáticas. $O$ autor destaca muitos casos em que o uso de animações apresentava vantagens em relação ao uso de imagens, observando, contudo, que as animações apresentavam mais informação do que as imagens estáticas (idem).

Frente a isso, não é difícil notar que uma animação geralmente contém mais informação do que uma imagem estática - a animação necessariamente apresenta informação temporal, isto é, uma dimensão que a mídia estática não explora. Por mais que seja possível inferir a existência da dimensão temporal a partir de uma imagem estática (como em sequências pictóricas), ela não está na mídia, e sim no processo de percepção do aprendiz. Outra questão pertinente é relativa ao público escolhido nos testes vigentes. Em experimento, Johnson et. al. selecionou determinado grupo (psicólogos) para resolver problemas referentes à outra área do conhecimento (Johnson; Mayer, 2009). Os autores notaram que isso afetou de maneira decisiva os resultados (os quais favoreciam imagens estéticas), concluindo que provavelmente não era do interesse deste público aprender sobre o tema apresentado na animação. Inversamente, por fim, é provável que os aprendizes não saibam utilizar e explorar cognitivamente uma animação, fato que muitas vezes não é levado em conta nas pesquisas.

Pontuamos ainda uma possível premissa elementar: existem usuários que preferem representações visuais e outros que preferem representações verbais, alguns preferem representações estáticas enquanto outros se identificam mais com representações dinâmicas etc. Isso porque devemos esclarecer que uma das questões aqui destacadas não se refere tanto à validade epistemológica do método em si, mas especialmente ao fato de que diversos autores replicam este método sem refletirem filosoficamente acerca do mesmo. Frente a isso, acreditamos que o designer, ao se apropriar de métodos de comparações cognitivas, não está apto para tomar conclusões baseadas unicamente nestes testes devido à sua formação insuficiente em psicologia cognitiva. Mesmo um psicólogo especialista em cognição, ao desenvolver estes testes, deve avaliar seus resultados com base em precedentes teóricos que estão por detrás dos métodos adotados. Não podemos afirmar que isso não ocorre, mas geralmente isso não é explicitado nos trabalhos publicados.

O que podemos é somente levantar, após o breve panorama apresentado, alguns questionamentos que julgamos pertinentes: se uma animação, por natureza dinâmica, sempre apresentará mais informação ao usuário (a informação temporal), por que compará-la a uma imagem estática? Retomando a crítica pós-positivista, até onde a hipótese de um pesquisador, mesmo que de maneira não intencional, Ihe influencia diretamente em seus resultados? Com relação ao aprendizado, quais critérios definem as traduções entre as mídias estática e dinâmica? $\mathrm{E}$, finalmente, com relação aos testes em si, como evitar que as informações não sejam omitidas ou reinterpretadas subjetivamente pelas particularidades de determinado público?

\section{Agradecimento}

Ao PPG-Design UFPR, em especial à professora Dra. Stephania Padovani, por permitir e apoiar este trabalho de natureza crítica-analítica.

\section{Referências}

BADDELEY, A. 1998. Human Memory: Theory and Practice (Revised edition). Boston: Allyn and Bacon.

BROADBENT, G. 1984. Design and Theory Building. In: Cross, N. (ed.) Developments in Design Methodology. UK: John Wiley.

BURTON, J. K.; MOORE, D. M.; MAGLIARO, S. G. 1996. Behaviorism and Instructional Technology. In: D.H. Jonassen (Ed.), Handbook of research for educational communications and technology. New York: Macmillan, p. 46-73.

COYNE, R. D. 1990. Objectivity and the design process environment and planning B. In: Planning and Design, v. 19, p. 361-371. 
CROSS, N. 1984. Developments in Design Methodology. UK : John Wiley. v. 5, p. 63-69.

1993. Science and design methodology: a review. In: Research in Engineering Design, 2007. Editorial: Forty years of design research. In: Design Studies, 28, p. 1-4.

DALEY, J. 1982. Design creativity and the understanding of objects. In: Design Studies, v. 3, n. 3, p. 133-137.

DALLACOSTA, A.; FERNANDES, A. M. de C.; BASTOS, R. C. 1998. Desenvolvimento de um software educacional para o ensino de química relativo à tabela periódica. In: Anais do IV Congresso RIBIE, Brasília. Disponível em: <http://www.lsm.dei.uc.pt/ribie/docfiles>, acessado em 10 abr. 2011.

DILNOT, C. 1982. Design as a socially significant activity: an introduction. In: Design Studies, v. 3, n. 3, p. 139-146.

DIXON, J. R. 1988. On a research methodology towards a scientific theory of design. In: Newsome, S. L.; Spillers, W. R.; Finger, S. (eds.) Design Theory "88. Berlin: Springer-Verlag.

ERTMER, P.; NEWBY, T. 1993. Behaviorism, cognitivism, constructivism: comparing critical features from an instructional design perspective. In: Performance Improvement Quarterly, v. 6, n. 4 , p. 50-72.

FONTOURA, A. M. 1997. As manifestações pós-modernistas no desenho industrial e suas repercussões no ensino do projeto de produto. Dissertação (Mestrado) - Curitiba: PUC-PR.

GALLE, P. 1999. Design as intentional action: a conceptual analysis. In: Design Studies, v. 20, n. 1, p. 57-82.

HEGARTY, M. 2004. Dynamic visualizations and learning: getting to the difficult questions. In: Learning and Instruction, v. 14, n. 3, p. 343-351.

HUBKA, V.; EDER, W. 1990. Design knowledge: theory in support of practice. In: Journal of Engineering Design, v. 1, p. 97-108.

JOHNSON, C. I.; MAYER, R. E. 2009. A Testing Effect With Multimedia Learning. In: Journal of Educational Psychology, v. 101, n. 3, p. 621-629. Disponível em: <http://www.scopus.com/inward/record.url?eid=2-s2.067949096058\&partnerlD=40\&md5=5745a8bc6c86f13dcb7da80ee9c04775>, acessado em 10 abr. 2011.

JONASSEN, D. H. 1991. Objectivism versus Constructivism: Do We Need a New Philosophical Paradigm? In: Educational Technology Research and Development, v. 39, n. 3, p. 5-14.

LIDDAMENT, T. 1999. The computationalist paradigm in design research. In: Design Studies, v. 20, n. 1, p. 41-56.

LOVE, T. 1998. Environmental and Ethical Factors in Engineering Design Theory: a Post positivist Approach. In: Praxis Education, Perth, Western Australia.

. 2000. Philosophy of Design: A Meta-theoretical Structure for Design Theory. In: Design Studies, 21, p. 293-313.

MARGOLIN, V. 1992. Design history or design studies: subject matter and methods. In: Design Studies, v. 13, n. 2, p. 104-116.

MAYER, R. E. 2005. Introduction to Multimedia Learning. In: R. E. Mayer (Ed.), The Cambridge handbook of multimedia learning. New York: Cambridge University Press, p. 1-16.

MAYER, R. E.; MORENO, R. 2002. Animation as an Aid to Multimedia Learning. In: Educational Psychology Review, v. 14, n. 1, p. 87-99.

OXMAN, R. 1999. Educating the designerly thinker. In: Design Studies, v. 20, n. 2, p. 105-122.

PAIVIO, A. 1986. Mental representations: A dual coding approach. England: Oxford University Press.

PHILLIPS, D. C.; BURBULES, N. C. 2000. Postpositivism and Educational Research. Lanham \& Boulder: Rowman \& Littlefield Publishers. 
PLATÃO. 2001. A República. In: Série Reencontro Filosofia. Trad. Marcelo Perine. São Paulo: Scipione.

SARGENT, P. 1994. Design science or nonscience. In: Design Studies, v. 15, n. 4, p. 389-402.

SMITH, P. L.; RAGAN, T. J. 1995. Instructional Design. 2 ed. New York: John Wiley \& Sons.

SWELLER, J. 1999. Instructional design in technical areas. Camberwell, Australia: ACER Press.

THOMAS, J. C.; CARROLL, J. M. 1979. The psychological study of design. In: Design Studies, v. 1, n. 1, p. 5-11.

TVERSKY, B.; MORRISON, J. B.; BETANCOURT, M. 2002. Animation: Can it facilitate? In: International Journal of Human-Computer Studies, n. 57, p. 247-262.

ZAMMITO, J. H. 2004. A Nice Derangement of Epistemes: Post-positivism in the study of Science from Quine to Latour. Chicago \& London: The University of Chicago Press.

\section{Sobre os autores}

Antônio Martiniano Fontoura, Doutor (Engenharia de Produção), UFPR: professor no curso de Mestrado em Design da UFPR, professor e coordenador do curso de Desenho Industrial da PUCPR e professor do ensino tecnológico da UTFPR. Com ênfase em Ensino do Design, atua principalmente nos seguintes temas: design, educação através do design, design de embalagem, embalagem e design e educação.

amfont@matrix.com.br

Marcos Namba Beccari, Mestre (Design), UFPR: professor no curso de Design da UniBrasil, interessa-se por Filosofia do Design, Teoria do Design e Estudos da Comunicação. Além de coordenar o blog Filosofia do Design, participa do projeto AntiCast, colabora com a revista Ciano e com os blogs Design Simples e Formas do Consumo.

contato@marcosbeccari.com

Tiago de Lima Oliveira, Mestre (Design), UFPR: professor no curso de Design da UniBrasil, interessa-se por Design Instrucional aplicado ao ensino de química orgâ nica, Teorias do Aprendizado e Filosofia do Design.

etsete@gmail.com 